\title{
THE CONCEPT OF PRIMITIVITY IN THE EARLY ANTHROPOLOGICAL WRITINGS OF A.P. ELKIN
}

\author{
Russell McGregor
}

'A civilized and a primitive race are in contact and, indeed, in clash'. ${ }^{1}$ These are the terms in which A.P. Elkin, in the 1930s, persistently described the problems of Aboriginal-European interaction in Australia. What did he mean by these words? And why did an anthropologist whose orientation was avowedly functionalist continually invoke the twin concepts of 'primitive' and 'race'? The key feature of functionalist anthropology was its synchronic approach to the study of clearly delimited units termed 'societies'. To this enterprise, what was the relevance of the inherently time-oriented notion of primitivity or the biologicallybased idea of race? Partly, it may have been that these concepts were items of intellectual baggage inherited from an earlier anthropology and not yet subjected to adequate disciplinary scrutiny by the new generation of scholars. ${ }^{2}$ Yet it was more than this. The concept of a primitive race performed a significant function in Elkin's functionalist anthropology. This paper examines some manifestations of the primitive race concept in Elkin's writings of the 1930 s, both as an item of inherited intellectual baggage and as an explanatory device to which he had frequent recourse.

The proximate origins of the concept of primitivity lay in 18th century Enlightenment ideas of progress. However, it was late 19 th century evolutionary theory which firmly established primitivity as a legitimate scientific construct. According to these anthropologists, the Aborigines of Australia represented the nadir of evolutionary development, although some preferred to award this dubious distinction to the inhabitants of Tierra del Fuego or the Hottentots of Africa. In the second and third decades of the 20th century, British social anthropologists began to turn their attention away from an evolutionary concern with reconstructing the past progress of mankind, devoting their efforts to explaining the functioning of indigenous societies in Africa, Asia and Oceania. However, the transition from evolutionary to functionalist anthropology marked more a reorientation of focus than a radical rejection of the older perspective. The creation of functionalist social anthropology was part of the increasing professionalisation of the discipline. While evolutionists were seen as spinning speculative accounts of the early history of mankind out of fragmentary information acquired at second or third hand from missionaries and travellers, the new generation of anthropologists demanded a more empirical, more 'scientific', approach to the study of society. This involved intensive fieldwork in specific, closely delimited social units, by trained observers who searched out

Department of History and Politics, James Cook University of North Queensland.

$1 \quad$ Elkin 1933, p. 8.

2 The anthropologist Gillian Cowlishaw adopted this perspective in her analyses of the persistence of the concept of race in Australian social anthropology. However, Cowlishaw's perspective was that of the anthropological 'insider', whose primary purpose was the reforming or reorientation of the discipline by pointing out the supposed errors of the past. While her accounts were both historically informed and perceptive, Cowlishaw's stance as internal disciplinary critic led her away from a full historical contextualisation of such figures as Elkin. Also, her major targets appear to have been a later generation of anthropologists, including the Berndts and Maddock. See in particular Cowlishaw $1988 \mathrm{a}, \mathrm{pp} .60-79$. See also Cowlishaw 1986 a, pp. 2-12; 1986 b, pp. 3-24; 1988 b. 
the mechanisms by which the society was kept smoothly running. ${ }^{3}$ The essentially historical aspirations of the evolutionists were abandoned in favour of a synchronic focus on the 'ethnographic present'. But while functionalists were critical of the conjectural excesses of evolutionary anthropology, they advanced no critique of its fundamental premises. Far from it. Functionalists were heavily indebted to evolutionary ideas, RadcliffeBrown going so far as to describe himself as one 'who has all his life accepted the hypothesis of social evolution as formulated by [Herbert] Spencer as a useful working hypothesis in the study of human society'. ${ }^{4}$ It was simply that Radcliffe-Brown and his colleagues, in their efforts to make their discipline more 'scientific', eschewed speculation about an ultimately unknowable past in favour of empirical evidence about a presumed-tobe knowable present.

Functionalist anthropology grew up in opposition to the diachronic approach of its evolutionary forebear; ${ }^{5}$ but not in opposition to the substantial evolutionary premise that human societies followed a developmental sequence, along which some societies had advanced further than others. Thus it was only too easy for the new anthropologists to adopt the same labels, and frequently to slip into the same conceptual world, as their predecessors. Some societies were more primitive - those were the ones anthropologists studied; some societies were more advanced - those were the ones anthropologists came from. How humanity had progressed from one to the other, which had been the central concern of the evolutionists, was relegated to the realm of speculation, beyond scientific inquiry. But the primitivity of such societies as the Australian Aboriginal remained a takenfor-granted fact.

Like primitivity, race was a concept which had its roots in the 18 th century and attained its most grandiose elaboration in the evolutionary science of the late 19th and early 20th centuries. Racial attributes and racial differences came to be accepted as fundamental to an understanding of the nature of humanity. Moreover, as Nancy Stepan has argued, the persistent tendency in science was to reify the racial category: to conceive races as real natural entities rather than as the constructs of scientific investigation. ${ }^{6}$ Although there were significant differences in the extent to which anthropologists actually invoked race as a determinative agency, as long as races continued to be regarded as 'real' entities, they comprised a legitimate part of scientific explanation. In Britain, a sustained attack on racial science did not get under way until the mid-1930s; even then, the tendency was to minimise the significance of racial differences rather than to challenge the fundamental assumption of the reality of race. ${ }^{7}$ This was well exemplified in the 1935 classic, We Europeans, co-authored by the social anthropologist A.C. Haddon and the evolutionary biologist Julian Huxley. The target of this polemic was Nazism; in particular, the authors attacked those doctrines which they regarded as perversions of racial science for Nazi propaganda purposes. Whatever critique there may have been of the concept of race itself, it was vastly overshadowed by criticism of its political misuse. ${ }^{8}$ Moreover, the views expressed by Huxley and Haddon were not necessarily representative of the British

3 See Langham 1981, pp. xi-xxx.

4 Radcliffe-Brown 1958, p. 189, cited in Stocking 1987, p. 293.

5 It also grew up in opposition to the equally diachronic perspective of diffusionism. However, diffusionism was a rather limited episode in the history of British social anthropology, and it failed to take root in the Australian scientific community.

6 Stepan 1982.

7 The same tendency is apparent in earlier attacks on racial ideas by the American anthropologist Franz Boas; see Stocking 1968, pp. 161-94. For an examination of the faltering steps by which racial science was dismantled in the 1930s, see Barkan 1992.

8 See Huxley \& Haddon 1935. 


\section{ELKIN'S EARLY ANTHROPOLOGICAL WRITINGS}

anthropological fraternity. Organised scientific opposition to Nazi doctrines in the 1930s floundered in Britain because of lack of agreement over the nature and significance of racial differences. ${ }^{9}$

The widening professional split in British anthropology, between the social and the physical branches of the discipline, probably contributed more to the persistence than to the challenging of racial ideas, at least in the short term. In carving out the study of 'primitive' societies as their own academic territory, social anthropologists left the study of racial differentiation of affinities to specialists in the field of physical anthropology. The distinction was not altogether novel; but in the writings of evolutionary anthropologists there had been a conflation of the racial with the cultural, the biological with the social. The boundaries between these two did not begin to become distinct until about the 1920 s, and then more as the outcome of disciplinary fission than of any sustained critique of the actual concepts. ${ }^{10}$ The fact that functionalist anthropologists focussed their attention on society did not mean that they denied the existence of inherent racial differences; merely that the detailed consideration of such matters lay outside their own disciplinary boundaries. The concepts of neither race nor primitivity were subjected to any searching critique; they were disengaged from the academic discourse of functionalism, but were pragmatically 'available' as occasion demanded.

It is notable that while the concepts of primitivity and race occupied no significant place in Elkin's academic studies of Aboriginal kinship systems and religious rituals, they figured prominently in his many writings advocating the cause of Aboriginal welfare. ${ }^{11}$ Paradoxical as it may seem from the perspective of the 1990s, it was when Elkin was in his humanitarian, social reformist mode that he leaned most heavily on the concepts of primitivity and race. For while a purely functionalist approach may have been well suited to the task of recording and analysing the workings of a presumed 'traditional Aboriginal society', it had serious limitations when applied to the practical task of resolving the 'Aboriginal problem'.

In the 1920 s and 1930 s, the practical value of social anthropology was enthusiastically promoted by its practitioners. Motives may well have been mixed. A new discipline claiming pragmatic relevance could expect better access to government funding than could one whose horizons were limited to the academy. Yet there is no reason to doubt that anthropologists like Radcliffe-Brown sincerely believed that their studies would benefit both the colonial rulers and the indigenous ruled. Before the Second World War the best interests of the two were seen as by no means incompatible, and anthropology was championed as a means of bridging the gap between administrator and native. ${ }^{12}$ In the postWar era of decolonisation, this close association of anthropology and imperialism became

9 Barkan 1988, pp. 190-5; see also Barkan 1992, pp. 285-96.

10 This is not to deny that a distinction between the social and the biological aspects of human existence had previously been made; it is rather to note that until the inter-war years, the distinction had been more hazy, enabling scientists to slide easily - and quite legitimately - from one to the other. It may also be pointed out that an absolute distinction between the two is not maintained even in the anthropology of the 1990s; the issue of 'Aboriginality', of major concem in current Australian anthropology, is one that appears to involve both a biological and a cultural dimension.

11 This division of Elkin's work is purely a matter of analytical convenience, by no means implying that his writings can be neatly divided into two mutually exclusive categories. His scientific works were strongly influenced by his humanitarian concern; his social reformist writings by his scientific outlook. Nonetheless, some of Elkin's publications consist almost exclusively of academic analyses of bodies of empirical data; others are explicitly aimed at reorienting popular opinion and administrative programs conceming the Aborigines. Compare, for example, his Studies in Australian Totemism 1934, with another publication from the same year, "The Aborigines, our national responsibility', pp. 52-60.

See for example Radcliffe-Brown 1930, pp. 267-80. 
the subject of considerable soul-searching on the part of anthropologists. ${ }^{13}$ Although the post-colonial critics seem to have often exaggerated the fidelity of the two parties, it can scarcely be doubted that there was an intimate relationship between functionalist anthropology and colonial administration. The historian of anthropology, Ian Langham, has remarked:

An anthropology with the avowed aim of uncovering the factors which kept societies in smoothly-functioning harmony, and a national colonial policy which imposed its will upon distant peoples by plugging into the indigenous political organisation, could not have been innocent playmates. ${ }^{14}$

However, the association here was between functionalism and a policy of indirect colonial rule, as in parts of Africa, where imperial authority and indigenous peoples remained geographically and culturally distinct. ${ }^{15}$ In this context the functionalist anthropologist undoubtedly had much to offer: he or she explained the social mechanics; the administrator operated the machine. In the very different Australian situation, where there was no question of indirect rule, where according to Elkin himself the Aboriginal social mechanism either had already broken down or soon would, functionalist anthropology had rather less to offer.

Far from being a matter of indirect rule over a distant people, Elkin's self-appointed task was to promote the incorporation of the Aborigines into the Australian nation. As belief in the 'doomed race' idea waned, there was growing pressure, from the late $1920 \mathrm{~s}$, for a long-range policy which would ensure a permanent place for Aborigines in Australian society. In addition, Elkin was motivated by an ardent Christian humanitarianism which demanded justice for the Aboriginal people. His 'positive policy for the future' was social assimilation. Whatever assimilation may have become in the hands of administrators after World War Two, for Elkin it was not simply the Europeanising of the Aborigines. Rather, it was a process by which Aborigines would be assisted to adjust to the circumstances of modern Australian society, in which process they would play 'an active part in working out a blend of their own and Western culture'. ${ }^{16}$ Certainly, the emphasis was on the Western ingredient of the blend; yet Elkin clearly saw that an insistence on the complete Westernisation of the Aborigine was symptomatic of 'an ignorant or conceited view of the universal application of our standards'. ${ }^{17}$ If Aborigines were to attain a fuller participation in the Australian nation, they had to be assisted over 'the difficult times of transition from the "old stone-age" to that higher stage of culture to which we desire to lead them' ${ }^{18}$ The 'higher cultural stage' was envisaged as very similar to that of the West; but it was not an exact replica.

Elkin's 'positive policy for the future' drew on three basic currents of anthropological thought: an evolutionist - perhaps better named progressivist - theme, which entailed a model of social change as a advancement from primitivity toward civilisation; a racial theme which posited inherent differences between human groups in terms of their capacities for such advancement; and a functionalist theme which envisaged social change as a piece-by-piece reassembly of the components of a social mechanism. The three

13 See for example Asad 1973. For more recent analyses of the relationship between imperialism and anthropology see Stocking 1991.

14 Langham 1981, p. xv.

15 A similar colonial relationship prevailed between Australia and Papua and New Guinea; and it is noteworthy that practical anthropology courses at the University of Sydney in the inter-war years were focussed squarely on Melanesian studies.

Elkin 1937, p. 500.

17 ibid., p. 478.

18 Elkin 1934b, p. 60. 


\section{ELKIN'S EARLY ANTHROPOLOGICAL WRITINGS}

currents did not always flow smoothly together. Indeed, the confusion which is apparent in many of Elkin's articles on Aboriginal welfare can best be understood in terms of the tensions between them. ${ }^{19}$ Nonetheless, in general terms, the evolutionist or progressivist view provided the basic framework. In Elkin's words, the task was 'to frame and put into operation a policy designed to raise them in the scale of civilisation'. ${ }^{20}$ Functionalism provided some guidance as to how this social change could be effected; ${ }^{21}$ while racial assumptions set the parameters of change.

Racial determinism was most salient in his earliest writings. In a series of articles published in 1929, significantly entitled 'The Practical Value of Anthropology', he adopted Pitt-Rivers' concept of 'culture-potential', an ill-defined notion which posited inherent differences in the capacities of various races to attain a 'high' cultural level and to adapt to changing social circumstances. Pitt-Rivers identified himself as 'generally speaking' a functionalist anthropologist; ${ }^{22}$ but more than anything else he exemplifies how readily oldfashioned racial determinism could be incorporated into new-fashioned functionalism. For Elkin, 'culture-potential' was an alluring concept, for it provided an explanation of the apparent failure of Aborigines to make a satisfactory adjustment to Western civilisation, while retaining the functionalist doctrine that every element of a society, every custom, belief, ritual and artefact, performed some essential role in the workings of the social mechanism. In his 'Practical Value' articles he maintained a conventional distinction between 'primitive' and 'civilised' peoples, explicitly relating this to differences of racial endowment. ${ }^{23} \mathrm{He}$ explained that:

The fundamental unity of human races ... does not mean that all races are biologically equal with respect to all their powers. Indeed ... there are differences. As already stated, some races possess certain powers in greater degree or in more individuals, or in both, than do others. Thus, the Australian Aborigines and the African negroes are human and have their powers, but they are not necessarily equal to the white or yellow races, especially as regards those traits which are most important for the development of advanced culture. ${ }^{24}$

The notion of innate racial attributes which delimited Aboriginal capacities for social 'advancement' remained a persistent theme in Elkin's writings throughout the 1930s. In his 1932 article, 'Cultural and Racial Clash in Australia', racial determinism was far less overt than in his 1929 'Practical Value' series. Yet he persisted in the view that Aborigines laboured under a racial handicap, maintaining that:

we must face the physiological fact that the aborigine is, generally speaking, endowed with a comparatively small size of brain, the average capacity of

19 Particularly in his earliest articles, where Elkin grappled with the thomy questions of the extent to which racial attributes may delimit a people's ability to progress and the potential relevance of functionalist anthropology to Australian problems, his arguments are notable more for their confusedness than their clarity; see for example "The practical value of anthropology' 1929. As he came to a more mature understanding of these issues, the confusedness was moderated in later articles, but did not disappear; see for example his 1937 article, 'Native education', especially pp. 484-500.

Elkin 1934c, p. 15.

21 As a practical discipline, functionalism emphasised the need to maintain a smoothly-running social system through times of socio-cultural change, and the need for scientific expertise in engineering the desired modifications. In line with these ideas, Elkin argued that the transformation of Aboriginal society required that the existing traditions and institutions be built upon, rather than torn down; see for example Elkin 1935, pp. 117-46; Elkin, 1934a, pp. 31-45; Elkin 1934c, pp. 1-18.

Pitt-Rivers 1927, p. 10

See especially Elkin 1929, pp. 36-7.

24 ibid., pp. 34-5. 


\section{ABORIGINAL HISTORY 1993 17:2}

which is twenty per cent less than ours. Now this implies a handicap in the brain machinery required for adaptation to and overcoming of, circumstances, especially such as have been introduced by a people whose brain capacity is so much higher. ${ }^{25}$

The adoption by Aborigines of a civilised way of life, according to Elkin, 'would appear to demand a gradual development of the brain-mechanism'. ${ }^{26}$ Although he did not use the term 'culture-potential' in this or any subsequent article, the essential idea of a connection between biology and culture remained. 'Thus the Australian aboriginal race', he wrote, 'is going down to biological history as another instance of a type which was so adjusted to, and specialized for, one environment, that it could not adapt itself to another'. ${ }^{27}$

Yet Elkin's acknowledgment of innate racial differences and deficiencies did not imply a denial of Aboriginal capacities for social advancement; it merely set the limitations and direction of that process. Racial impediments may have prevented Aborigines from becoming fully Europeanised; it would not prevent them from becoming civilised. In his review of Porteus's Psychology of a Primitive People, he asserted that:

There is no reason for expecting that our civilisation in all its developments would be the most suited to the aborigines; there are racial differences and inequalities, but this does not necessarily imply, as Porteus categorically states, that the aborigines are certainly unadaptable to a civilised environment.' After all, there are other types of civilised environment, and any race must ultimately develop its own from within. ${ }^{28}$

In Elkin's conception, 'civilisation' for the Aborigines entailed no radical departure from Western norms. It seems that he envisaged an Aboriginal acquisition of the essentials of European economic, religious and social forms, while retaining the trappings of Aboriginal art, ceremonial and culture. He insisted that 'the best in their own religion' should be retained, ${ }^{29}$ and that 'what was of social and moral value in the native order' should be appreciated. ${ }^{30}$ The value judgements were being made from a self-confidently superior European perspective. Fundamentally, Elkin's notion of a distinctively Aboriginal form of 'higher culture' was a compromise between the competing demands of the necessity for social progress and the innate impediments of race.

Over the course of the 1930 s the theme of racial determinism in Elkin's writings became more and more attenuated. It did not disappear, but became more of a problem which lurked in the background of his developing social assimilationist perspective. In his 1937 article on 'Native Education' he argued for the implementation of ambitious educational schemes which would provide Aborigines with a means of access to the wider Australian society. His optimism on this score, however, was tempered with doubts: 'so far they [the Aborigines] have shown little power to adapt themselves to our culture; there may be biological reasons for this, for their adaptation to aboriginal life may have become part of their very physiological make-up'. ${ }^{31}$ Race remained a sufficiently important issue for Elkin to devote the first chapter of his 1938 book, The Australian Aborigines: How to Understand Them, to the topic. It was a conventional summary of physical features, racial origins and affinities, in which he included the remark:

Elkin 1932a, p. 38.

ibid, p. 39.

ibid., pp. 37-8.

Elkin 1932b, p. 112.

Elkin 1934b, p. 60.

Elkin 1937, p. 500.

ibid., p. 496; see also pp. 470, 498-9. 


\section{ELKIN'S EARLY ANTHROPOLOGICAL WRITINGS}

The question 'Are the Aborigines the lowest race of mankind?' is not easily answered. Physically, they have some primitive features, for example, the thickness of the skull-bones, the shape of the face, the retreating nature of the forehead and the comparatively small brain. ${ }^{32}$

By this stage of Elkin's career, the significance of such matters had been considerably moderated, as he had come to place emphasis more on the socio-cultural determinants of primitivity. In his preface to the book, in which he urged white Australians to adopt a respectful appreciation of Aboriginal people, he declared that: 'Some folk carry the metaphor of a child-race too far'. Clearly, he believed that the metaphor did carry some validity; but how far could it be legitimately carried? Elkin provided an answer:

A child-race is so called because it has not attained to the stature of our civilisation; its grown men and women, however, are adults; they do not think as children but as social personalities who are responsible for the development and maintenance of the social, economic and religious life of their community. ${ }^{33}$

Behind the banal phraseology there was a significant point: Aborigines were a primitive people, but their lack of development was, primarily at least, at a social rather than at an individual, biological level.

Even in his earliest writings, where racial determinism was at its strongest, sociocultural factors were awarded considerable prominence. In his 1929 'Practical Value' series he expressed puzzlement over the relative significance of race and culture in determining a people's characteristics. Three years later, in 'Cultural and Racial Clash', his views were still equivocal, although expressed without the same degree of bewilderment. Alongside his assertion of inherent racial limitations, he propounded a straightforward view of social progress, resonant with the principles of 18 th century stage theory:

The position demands that if he [the Aborigine] is to survive, he must pass with great rapidity from the food-gathering stage of complete dependence on nature, and from the socio-mystical organization of tribal life, to a stage in which nature is exploited, and in which mechanization and economics control the outlook on nature and society. ${ }^{34}$

Over the succeeding years Elkin gave increasing prominence to the economic aspect of Aboriginal primitivity. He came to qualify the adjectives 'primitive' and 'civilised' in explicitly economic terms, referring to 'their peculiar primitive food-collecting stage of economic life', ${ }^{35}$ and to the 'cultural clash which has arisen from the invasion of a primitive food-gathering people's country by a civilised, agricultural and industrial people'. 36

Indeed, the shift in Elkin's interpretation of Aboriginal primitivity over the course of the 1930 s was primarily a shift from a racial to an economic perspective. As a functionalist anthropologist he insisted that the economic aspects of life were inextricably intertwined with religious beliefs, kinship systems and so forth. Yet he was prepared to go some way toward awarding primacy to economics as a determinant of other socio-cultural attributes, arguing that: "The Australians are a food-gathering people, and around their peculiar economic position their social organization and religious life are orientated'. ${ }^{37} \mathrm{He}$ maintained that Aboriginal life

32 Elkin 1938, pp. 19-20.

33 ibid., p. vi.

34 Elkin 1932a, p. 38.

35 Elkin 1937, p. 468.

36 Elkin 1938, p. 21.

37 Elkin 1937, p. 472. 


\section{ABORIGINAL HISTORY $1993 \quad 17: 2$}

has been adjusted to one set of economic conditions - food-gathering - and great skill is evinced in it. Skill, however, is not sufficient. The aborigine realizes that nature varies and that he is dependent on her, and so his 'philosophy of life' has become closely interwoven with nature and his foodgathering efforts. ${ }^{38}$

A corollary of this economic view of Aboriginal primitivity was an emphasis on economic development as a key aspect of social progress. Elkin strongly endorsed an educational system which would provide Aborigines with

a knowledge of the significance of time, and the value of money, ... teaching him to recognize the significance of contract [and] eradicating the nomadic background and developing the community sense centred upon the provision of a home for the individual and his family and the exploitation of the soil and domestic animals as a source of food supply. 39

As Elkin came increasingly to the view that the culture of the Aborigines depended more on their economic circumstances than on their innate racial attributes, he became more optimistic about their prospects for social 'advancement'.

In line with this trend, Elkin attempted to rebut the prevalent assumption of an ineradicable nomadic instinct, which, he claimed, had 'become quite a shibboleth where Australian aborigines are concerned'. 40 As early as 1934 he pointed out that 'too much emphasis can be laid ... on the nomadic aspect of aboriginal life'. ${ }^{41}$ Later in the decade, his arguments were more explicit and more comprehensive. The nomadic habit was, he wrote:

often referred to in terms which imply that it is biologically and ineradicably rooted and is therefore an insuperable bar to progress. But after all, it is not the fundamental thing about the aborigines for it is itself a consequence of their food-gathering manner of life ... The nomadic feature of the life of some primitive peoples is not the expression of a fundamental instinct; it is a cultural trait which food-producing (horticulture and agriculture) changes, but which pure pastoralism may accentuate; the cause of this again is economic and geographical. ${ }^{42}$

Continuing the Enlightenment theme, Elkin argued that if the appropriate circumstances were provided, Aborigines would adopt a settled life of agriculture and industry. $\mathrm{He}$ returned to the issue in his 1938 monograph on the Aborigines:

This point requires emphasis; the nomadic aspect of Aboriginal life is not biologically founded, but is culturally, in short, economically, determined. If the means of gaining a livelihood be changed, then the characteristics of nomadism will be changed. ${ }^{43}$

For Elkin, the basic task was to raise a primitive, nomadic food-gathering people to the 'higher cultural stage' of settled agriculture and industry. The conception was as old as the earliest humanitarian and missionary endeavours in Australia. These had failed, he believed, because they lacked the insights of a modern, scientific approach to the problems of 'cultural and racial clash'. Elkin's assimilationist program was founded, in more senses than one', on an assured faith in Progress.

ibid., p. 463.

ibid., p. 483.

ibid., pp. 467-8.

Elkin 1934 c, p. 16.

Elkin 1937, pp. 462-3.

Elkin 1938, p. 14. 


\section{ELKIN'S EARLY ANTHROPOLOGICAL WRITINGS}

Professor A.P. Elkin was not an original, creative theoretician. He was, rather, a diligent worker who advanced the status of anthropology and the cause of Aboriginal welfare by perseverance and dogged toil. His efforts on behalf of a 'primitive people' whose lives had been upturned by the incursion of civilisation were inspired, most fundamentally, by an ardent Christian humanitarianism. Science was harnessed to the cause; so, too, were whatever currents of thought came to hand. The concepts of race, culture, evolution and society were all called into service, and in the 1930s all were legitimate elements of anthropological explanation. His eminent colleagues and contemporaries such as Radcliffe-Brown and Malinowski had devised sophisticated methodologies for the study of human societies; but for an understanding of the overarching process of social change he turned to the much older tradition of evolution - or rather, of progress. His 'positive policy for the future' was framed in the explicitly progressivist terms of raising a 'primitive' people to a 'higher' cultural stage. Its most notable features are not innovativeness or novelty, but the common-places of the idea of progress which echo back through 19 th century evolutionism to the 18 th century Enlightenment.

\section{LIST OF REFERENCES}

Asad, T. (ed.) 1973, Anthropology and the Colonial Encounter, London.

Barkan, E. 1988, 'Mobilizing scientists against Nazi racism, 1933-1939' in Bones, Bodies, Behavior: Essays on Biological Anthropology, ed. G.W. Stocking. Madison, pp.180-205.

Barkan, E. 1992, The Retreat of Scientific Racism: Changing Concepts of Race in Britain and the United States between the World Wars, Cambridge.

Cowlishaw, G. 1986a, 'Aborigines and anthropologists', Australian Aboriginal Studies, no. 1, pp.2-12.

1986b, Race for exclusion', Australian and New Zealand Journal of Sociology, vol. 22, no. 1, pp. 3-24.

1988a, 'Australian Aboriginal studies: The anthropologists' accounts', Sydney Studies in Society and Culture, no. 4, pp. 60-79.

1988b, Black, White on Brindle: Race in Rural Australia, Cambridge.

Elkin, A.P. 1929, "The practical value of anthropologyt, Morpeth Review, part 1: vol. 1, no. 7, pp. 23-

33; part 2: vol. 1, no. 8, pp. 44-7; part 3: vol. 1, no. 9, pp. 33-44; part 4: vol. 1, no. 10, pp. 43-50. 1932a, 'Cultural and racial clash in Australia', Morpeth Review, no. 21, pp. 35-45.

1932b, "The social life and intelligence of the Australian Aborigine: A review of S.D.

Porteus's "Psychology of a Primitive People" ', Oceania, vol. 3, no. 1, pp. 101-13.

1933, A Policy for the Aborigines, Morpeth, NSW.

1934a, 'Missionary policy for primitive peoples', Morpeth Review, vol. 3, no. 27, pp. 31-45.

1934b, 'The Aborigines, our national responsibility', The Australian Quarterly, vol. 6, no. 23,

pp. 52-60.

1-18.

1934c, 'Anthropology and the future of the Australian Aborigines', Oceania, vol. 5, no. 1, pp.

1934d, Studies in Australian Totemism, Oceania Monograph no. 2, Sydney.

1935, 'Civilized Aborigines and native culture', Oceania, vol. 6, no. 2, pp. 117-46.

1937, 'Native education, with special reference to the Australian Aborigines', Oceania, vol. 7 ,

no. 4, pp. 459-501.

1938, The Australian Aborigines: How to Understand Them, Sydney

Huxley, J.S. \& Haddon, A.C. 1935, We Europeans: A Survey of "Racial" Problems, London.

Langham, I. 1981, The Building of British Social Anthropology: W.H.R. Rivers and his Cambridge

Disciples in the Development of Kinship Studies, 1898-1931, Dordrecht, Netherlands. 
Pitt-Rivers, G.H. Lane-Fox 1927, The Clash of Culture and the Contact of Races: An Anthropological and Psychological Study of the Laws of Racial Adaptability, with Special Reference to the Depopulation of the Pacific and the Government of Subject Races, London.

Radcliffe-Brown, A.R. 1930, 'Applied anthropology' in Report of the Twentieth Meeting of the Australian and New Zealand Association for the Advancement of Science, pp. 267-80.

Stepan, N. 1982, The Idea of Race in Science: Great Britain, 1800-1960, London.

Stocking, G.W. 1968, Race, Culture, and Evolution: Essays in the History of Anthropology, New York.

1987, Victorian Anthropology, New York.

(ed.) 1991, Colonial Situations: Essays on the Contextualization of Ethnographic Knowledge, Madison. 